\title{
Author Correction: Frontotemporal coordination predicts working memory performance and its local neural signatures
}

Ehsan Rezayat (D), Mohammad-Reza A. Dehaqani (iD, Kelsey Clark, Zahra Bahmani, Tirin Moore (i) \&

Behrad Noudoost (10)

Correction to: Nature Communications https://doi.org/10.1038/s41467-021-21151-1, published online 17 February 2021.

The original version of this article contained an error in Fig. 1, in which for the two left-hand plots depicted in Fig. 1c, the time labels (and associated dotted lines) on the $x$-axis were incorrectly shifted to the right.

The correct version of Fig. 1 is:

a
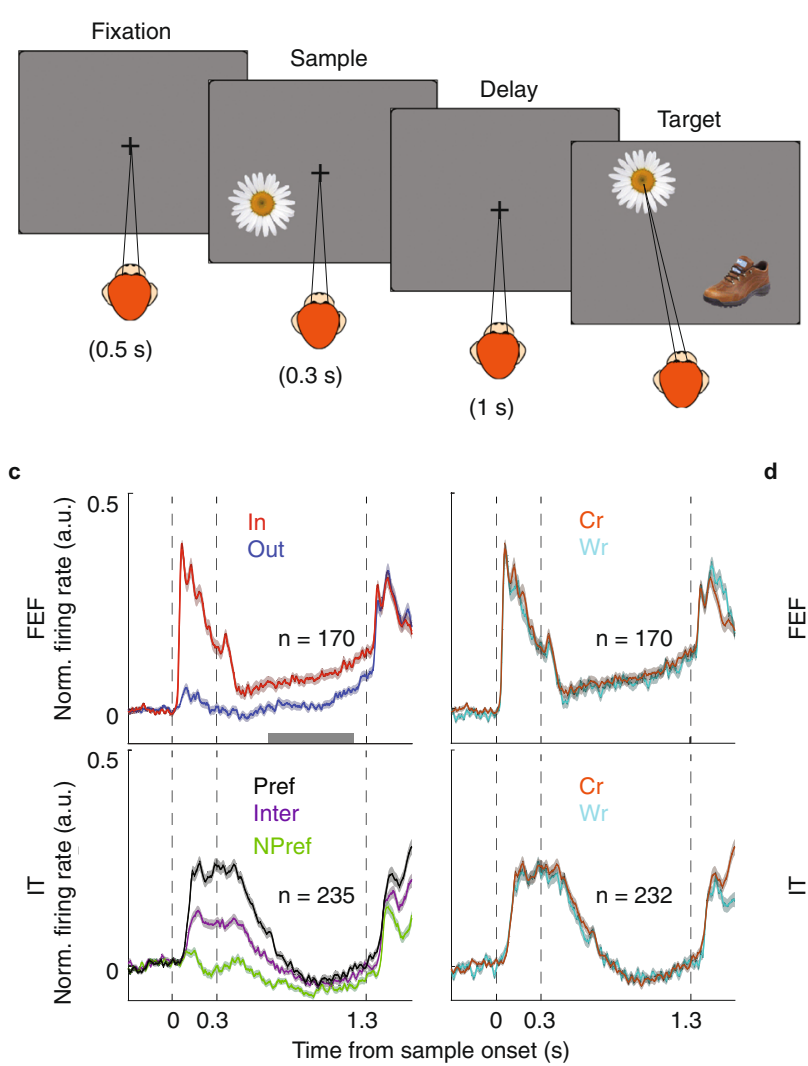

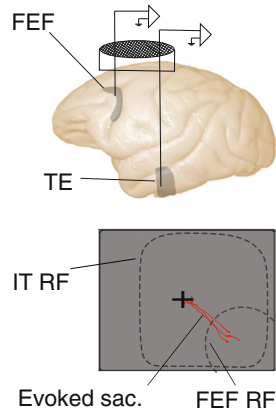

b

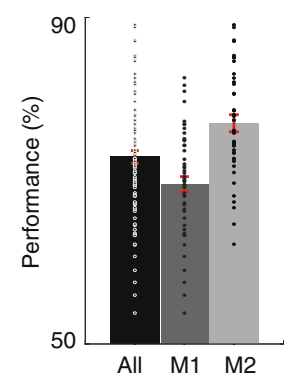

$\mathrm{Wr}$

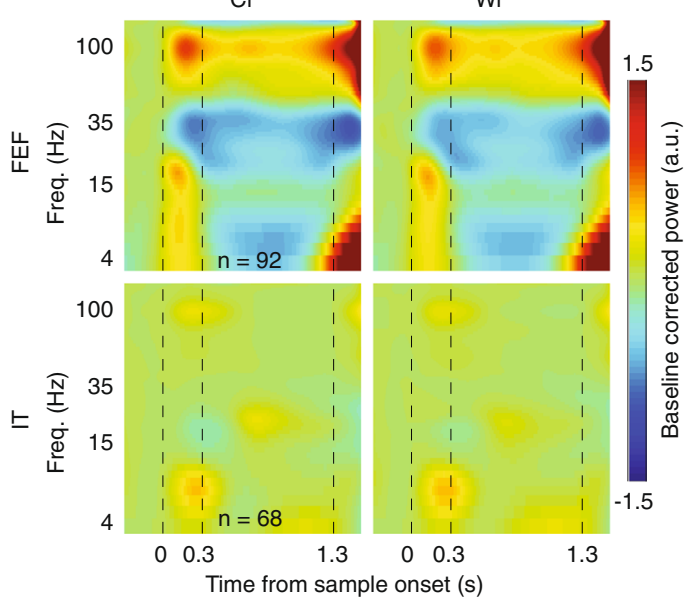


which replaces the previous incorrect version:

a

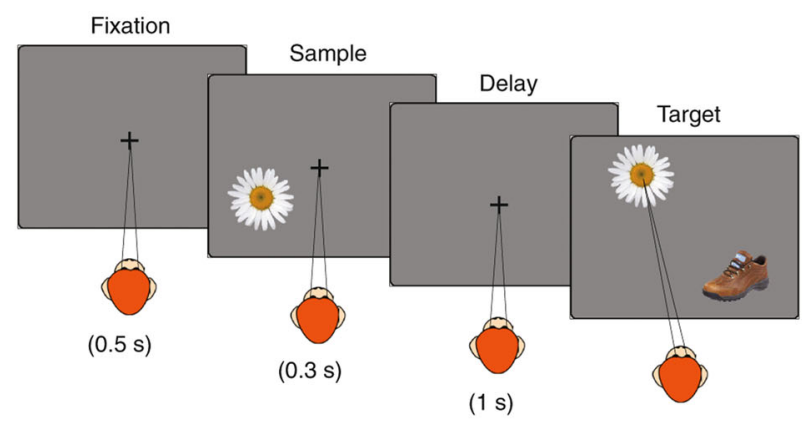

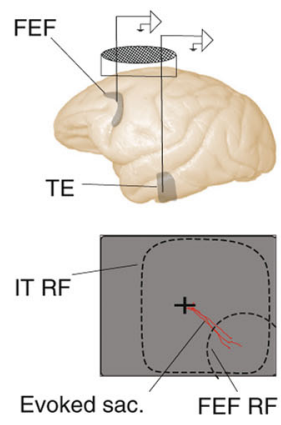

b

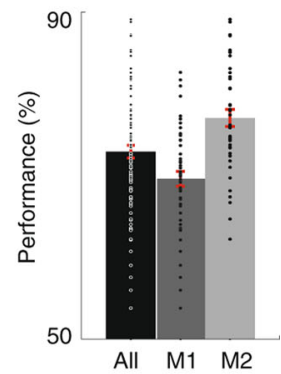

c

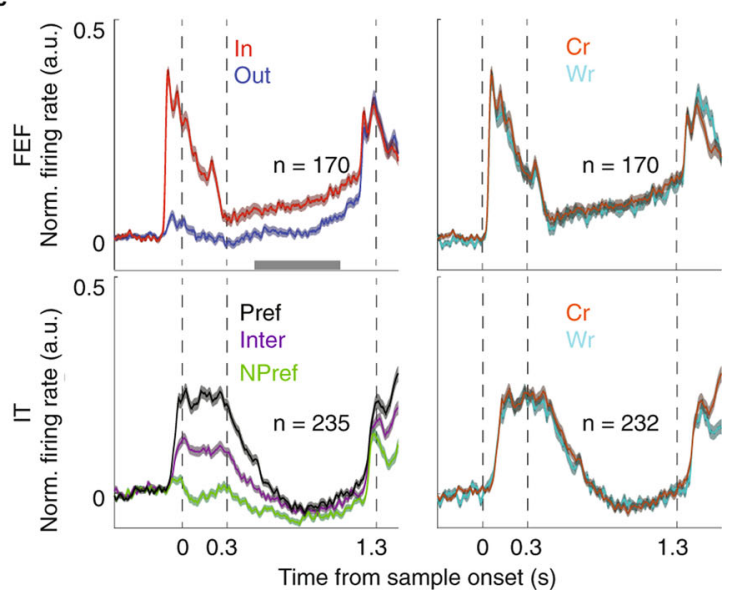

d
$\mathrm{Cr}$

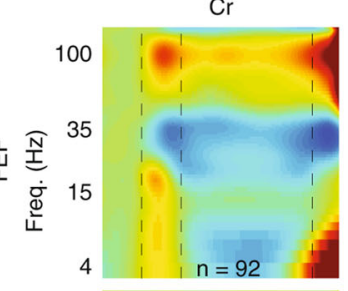

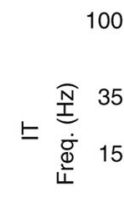

$\mathrm{Wr}$

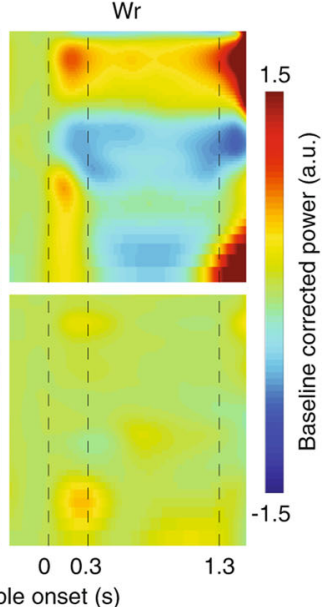

This has been corrected in both the PDF and HTML versions of the Article.

Published online: 15 June 2021

(c) Open Access This article is licensed under a Creative Commons Attribution 4.0 International License, which permits use, sharing, adaptation, distribution and reproduction in any medium or format, as long as you give appropriate credit to the original author(s) and the source, provide a link to the Creative Commons license, and indicate if changes were made. The images or other third party material in this article are included in the article's Creative Commons license, unless indicated otherwise in a credit line to the material. If material is not included in the article's Creative Commons license and your intended use is not permitted by statutory regulation or exceeds the permitted use, you will need to obtain permission directly from the copyright holder. To view a copy of this license, visit http://creativecommons.org/licenses/by/4.0/.

(C) The Author(s) 2021 